\title{
Human Cells, Tissues, and Cellular and Tissue-Based Products from Musculoskeletal Tissue
}

National Cancer Institute

\section{Source}

National Cancer Institute. Human Cells, Tissues, and Cellular and Tissue-Based Products from Musculoskeletal Tissue. NCI Thesaurus. Code C133364.

Human Cells, T issues, and Cellular and T issue-Based Products (HCT/Ps) from the human muscular and skeletal system. 